\title{
Role of Phospholipid Transfer Protein in High-Density Lipoprotein-Mediated Reverse Cholesterol Transport
}

\author{
Amirfarbod Yazdanyar • Calvin Yeang • \\ Xian-Cheng Jiang
}

Published online: 2 March 2011

(C) Springer Science+Business Media, LLC 2011

\begin{abstract}
Reverse cholesterol transport (RCT) describes the process whereby cholesterol in peripheral tissues is transported to the liver where it is ultimately excreted in the form of bile. Given the atherogenic role of cholesterol accumulation within the vessel intima, removal of cholesterol through RCT is considered an anti-atherogenic process. The major constituents of RCT include cell membrane- bound lipid transporters, plasma lipid acceptors, plasma proteins and enzymes, and lipid receptors of liver cell membrane. One major cholesterol acceptor in RCT is high-density lipoprotein (HDL). Both the characteristics and level of HDL are critical determinants for RCT. It is known that phospholipid transfer protein (PLTP) impacts both HDL cholesterol level and biological quality of the HDL molecule. Recent data suggest that PLTP has a site-specific variation in its function. Moreover, the RCT pathway also has multiple steps both in the peripheral tissues and circulation. Therefore, PLTP may influence the RCT pathway at multiple levels. In this review, we focus on the potential role of PLTP in RCT through its impact on HDL homeostasis. The relationship between PLTP and RCT is expected to be an important area in finding novel therapies for atherosclerosis.
\end{abstract}

Keywords Reverse Cholesterol Transport (RCT) . Phospholipid Transfer Protein (PLTP) · High Density Lipoprotein (HDL) · Atherosclerosis · Cholesterol efflux

\footnotetext{
A. Yazdanyar $\cdot$ C. Yeang $\cdot$ X.-C. Jiang

Department of cell Biology,

SUNY Downstate Medical Center,

450 Clarkson Ave. Box 5,

Brooklyn, NY 11203, USA

\section{X.-C. Jiang $(\bowtie)$}

Downstate Medical Center,

450 Clarkson Ave. Box 5,

Brooklyn, NY 11203, USA

e-mail: XJiang@downstate.edu
}

\section{Introduction}

Atherogenesis is initiated by accumulation of cholesterolrich lipid strikes in the arterial wall [1]. Many processes have been implicated in early atherogenesis, including lipoprotein oxidation [2, 3], aggregation and retention [4-7], endothelial alteration [1], monocyte recruitment, and foam cell formation [1]. Subsequent self-perpetuating chronic inflammatory response leads to further immune reactions and lipid deposition, which lead to atherosclerosis. One defense mechanism for atherosclerosis is removal of cholesterol from the vessel intima via reverse cholesterol transport (RCT).

The general concept of RCT involves transport of cholesterol from peripheral tissues and cells to the liver, transforming it into bile acids, and finally eliminating it from the body. RCT may prevent the formation and development of atherosclerosis by decreasing cholesterol levels in the plasma and in the wall of arteries. The RCT pathway consists of multiple factors. First, there are lipid transporters, which efflux cholesterol from peripheral tissues [8-10]; second, there are lipid acceptors, such as high-density lipoprotein (HDL) and its various subclasses [8-11], which act as a mediator between peripheral tissues and the liver; third, there are lipoprotein-associated proteins and enzymes, such as lecithin: cholesterol acyltransferase (LCAT) [12], cholesteryl ester transfer protein (CETP), and phospholipid transfer protein (PLTP) [13], which are involved in HDL remodeling and metabolism; and fourth, there are liver receptors such as scavenger receptor class B type I (SR-BI), which are important in removing cholesterol from the circulation [14].

There is a growing body of evidence suggesting that HDL mediates its atheroprotective effect through driving cholesterol efflux from macrophage foam cells that reside in vessel intima $[11,15,16]$. As a plasma cholesterol 
acceptor, both the biological activity and concentration of HDL particles are equally important to accomplish its atheroprotective effect $[8,17,18]$. Therefore, several cellular and plasma transfer proteins that are involved in the process of the formation and remodeling of HDL play a pivotal role in cholesterol efflux from macrophages. Among the different transfer proteins that are active either at cell membrane or in the circulation, PLTP and CETP have long been studied for their remarkable role in HDL metabolism. This review is mainly focused on the latest data regarding the role of PLTP in HDL-mediated RCT.

\section{Reverse Cholesterol Transport}

RCT is a potent defense mechanism against cholesterol accumulation in peripheral tissues [19]. This process involves the centripetal transport of excess cholesterol and phospholipid from peripherally settled macrophages to the liver for further metabolism and excretion through the bilefecal route $[11,16]$. The first step of RCT is efflux of free cholesterol from macrophages and other peripheral cells to extracellular cholesterol acceptors $[19,20]$. There are four different pathways that work together to carry cholesterol out of the macrophages to plasma acceptors. The major route is through ATP-binding cassette (ABC) A1- and ABCG1-mediated unidirectional active transport of free cholesterol toward apolipoprotein A-I (apoA-I)-rich, lipidpoor apolipoproteins (pre $\beta$-HDL) or HDL particles, respectively $[21,22]$. SR-BI and aqueous diffusion also promote efflux of the excess cholesterol in a passive bi-directional manner to mature HDL particles [23]. Macrophages and foam cells have extensive contribution in pathogenesis of the atherosclerotic lesions, and efflux of cholesterol from these cells has been shown to have a significant role in regression of an existing atheroma and reversing the process of atherosclerosis [16]. In order to accomplish RCT, the interaction between extracellular acceptors and cell surface transporters is very critical [20]. During this step of RCT, free cholesterol can be transferred to pre $\beta$-HDL, and the HDL bound cholesterol is subsequently esterified by LCAT. Accumulation of cholesteryl ester in pre $\beta$-HDL converts it to the larger, spherical mature HDL particles that are then taken up by the liver via the SR-BI [14, 24]. Alternatively, the cholesteryl ester can be transferred from HDL to low-density lipoprotein (LDL), and the later can be taken up by LDL receptors. The concentration and composition of extracellular cholesterol acceptors are determinants of the rate of cholesterol efflux. Furthermore, plasma proteins such as PLTP, CETP, and lipases are essentially involved in the process of HDL formation, conversion, and remodeling. Therefore, these proteins actively maintain the plasma level and biological properties of HDL particles and potentially play an important role in RCT.

\section{High-Density Lipoprotein and Reverse Cholesterol Transport}

A high HDL cholesterol level has been mentioned as an anti-atherogenic factor in progressive cohort studies and in randomized clinical trials aimed at raising HDL levels. Moreover, acute infusion of synthetic HDL or its principal apolipoprotein, apoA-I, can induce the regression of atheromatous plaque in humans. Indeed, there has been a wealth of research demonstrating the beneficial processes in which HDL participates. HDL plays a key role in RCT and, importantly, facilitates the removal of cholesterol from intra-lesion macrophages [25]. In addition, HDL has been shown to protect against LDL-induced monocyte migration into the sub-endothelial space in an endothelial cell/smooth muscle cell co-culture system [26]. This is consistent with the finding that HDL can blunt expression of endothelial cell adhesion molecules [27]. HDL can protect against oxidation of LDL or phospholipids [28]. Other aspects of HDL function that are protective against atherosclerosis include promoting endothelial function by stimulating nitric oxide synthesis [29] and preventing platelet aggregation and thrombin formation [30]. There are multiple aspects of HDL function that are anti-atherogenic, and its role in RCT is one of them. Different subclasses of HDL play major roles as cholesterol acceptors in the extracellular region and plasma [31]. Interestingly, a growing body of evidence has shown that fruitful cholesterol efflux is dependent both on high level of HDL cholesterol and on biological quality of different HDL particles [17, 18]. The biological quality refers to the size, shape, and composition of HDL particles, which are notably various and dynamically inter-convertible [32]. Evidently, each of the different pathways of cholesterol efflux prefers a specific subclass of the HDL particles as a cholesterol acceptor [32]. Therefore, the presence of different HDL subspecies and dynamic conversion between these subspecies are determinants for RCT. Human and mouse studies have pointed out that pre $\beta$-HDL and mature HDL are the major cholesterol acceptors in plasma [32]. Pre $\beta$-HDL is produced by interaction, and subsequent lipidation, of lipid-poor apoA-1 by ABCA1 or by HDL particle remodeling in the circulation $[19,32]$. One pathway for HDL particle remodeling involves plasma PLTP. PLTP fuses HDL particles generating larger HDL particles with concomitant production of small pre $\beta$-HDL [33]. Given its role in HDL metabolism, PLTP's role in reverse cholesterol transport deserves to be addressed. 


\section{Phospholipid Transfer Protein}

The relationship between PLTP structure and function is far from resolved. However, some progress has been made. PLTP belongs to a family of lipid transfer/lipopolysaccharide binding proteins including lipopolysaccharide binding protein (LBP), bactericidal/permeability increasing protein (BPI), and CETP [34].

In terms of lipid transfer activity, PLTP has its own characteristics. It has no neutral lipid transfer activity. PLTP circulates bound to HDL and mediates the net transfer of phospholipids between unilaminar vesicles into HDL and also the exchange of phospholipids between lipoproteins. The net transfer of phospholipid into HDL results in the formation of larger, less dense species. Plasma PLTP is also a nonspecific lipid transfer protein. Several studies have indicated that PLTP is capable of transferring all common phospholipids. Besides phospholipids, diacylglycerol, $\alpha$-tocopherol, cerebroside, and lipopolysaccharides are likewise transferred efficiently [35]. Although CETP also can transfer phospholipids, there is no redundancy in the functions of PLTP and CETP in the mouse model [36].

\section{The Effect of PLTP Overexpression on HDL Metabolism}

Overexpression of PLTP in mice was achieved by adenovirus and adenovirus-associated virus (AAV)-mediated infection. The former resulted in a 10- to 40 -fold increase in plasma PLTP activity [37, 38]. These mice were characterized by increased pre $\beta$-HDL levels but decreased $\alpha$-HDL cholesterol levels. PLTP expression mediated by AAV showed a prolonged pattern of overexpression that resulted in a significant decrease of total cholesterol and HDL cholesterol in C57BL/6 mice [38]. Transgenic mice that overexpress human PLTP at high levels were also generated. Compared with wild-type mice, they showed a 2.5- to 4.5-fold increase in PLTP activity in plasma. This resulted in a $30 \%$ to $40 \%$ reduction of plasma $\mathrm{HDL}$ cholesterol levels. Incubation of plasma from PLTP transgenic animals at $37^{\circ} \mathrm{C}$ revealed a two- to threefold increase in the formation of pre $\beta$-HDL compared with the plasma from wild-type mice [39]. Overall, PLTP overexpression causes a significant reduction of HDL levels in the circulation.

\section{The Effect of PLTP Deficiency on HDL Metabolism}

So far, no PLTP deficiency has been found in humans. The most useful information about PLTP deficiency was obtained from PLTP gene knock out (KO) mice, which demonstrated a complete loss of phosphatidylcholine (PC), phosphatidylethanolamine (PE), phosphatidylinositol (PI), sphingomyelin (SM), as well as a partial loss of free cholesterol (FC) transfer activities [40]. Moreover, the in vivo transfer of ${ }^{3} \mathrm{H}$ phosphatidylcholine, either from very low-density lipoprotein (VLDL) or HDL, was eliminated in PLTP KO mice. On a chow diet, these mice showed a marked decrease in HDL PL, FC, and apoA-I, demonstrating the important role of PLTP-mediated transfer of surface components of triglyceride-rich lipoprotein in the maintenance of HDL levels [40]. Additionally, the HDL of the PLTP KO animals was enriched with protein and poor in PC, and turnover studies showed a fourfold increase in the catabolism of HDL protein and CE compared with wildtype mice [41, 42]. Overall, PLTP deficiency also causes a significant reduction of HDL cholesterol and phospholipid levels in the circulation.

\section{PLTP and Atherosclerosis}

Both the physiologic function of PLTP in lipid homeostasis and the pathologic role of PLTP in atherosclerosis development are still being elucidated. PLTP expression is increased in different pathologies associated with increasing risk of coronary heart disease (CHD), such as obesity, insulin resistance, and type I and type II diabetes [43]. In a cross-sectional study, it was reported that serum PLTP activity is increased in CHD patients [44]. Moreover, PLTP activity is positively correlated with left ventricular systolic dysfunction [45] and low HDL levels [46]. Contradictorily, it also has been reported that lower PLTP activity without significant change in total PLTP mass is a risk factor for peripheral atherosclerosis [47]. Another study also has shown that low PLTP is a risk factor for peripheral atherosclerosis [48]. Importantly, a recent genome-wide association (GWA) study has identified a single nucleotide polymorphism (SNP) near the PLTP gene that is associated with HDL and triglyceride (TG) levels. Interestingly, the variant associated with higher HDL and lower TG also correlated with higher PLTP transcript levels in the liver [49]. This is the first evidence for a direct link between PLTP and lipoprotein levels in humans. The effects on HDL levels are consistent with the transgenic mouse studies $[40,50]$, but the apparent lowering of triglyceride levels in association with increased PLTP expression was not predicted.

Valenta et al. [51] demonstrated that macrophage PLTP alone has an atheroprotective effect in systemic PLTPdeficient mice. This phenotype could be explained via enhanced interaction of PLTP and ABCA1, which results in stabilized HDL binding to ABCA1 and increased rate of cholesterol and phospholipids efflux [52, 53]. Macrophagesecreted PLTP also increases the concentration of pre- $\beta$ HDL within the arterial intima [54]. However, in a similar setting, another study showed opposite results. In the study of Vikstedt et al. [55], macrophage-secreted PLTP had an 
atherogenic function. The main cause of reduced lesion size in this study was due to lack of PLTP activity in macrophages [55].

It has been reported that immunoreactive PLTP was detected in histologic sections of human carotid artery [56, 57], where it is co-localized with CD-68-positive macrophages, suggesting in situ production. Synthesis of PLTP was further demonstrated in cultured macrophages, and its expression was upregulated by acetylated LDL treatment $[58,59]$. Moreover, in the atherosclerotic segments, PLTP accumulated in extracellular matrixes, co-localizing with apoA-I, apoE, and biglycan. These findings suggested that PLTP might promote the binding of HDL to biglycan [57]. PLTP enhances cell-surface binding and remodeling of HDL, improving its ability to promote cholesterol and phospholipid efflux [53]. As underscored by recent bone marrow transplantation studies, local PLTP expression in macrophages could be protective as long as systemic PLTP levels are not markedly elevated [51, 55, 60]. Therefore, this set of data indicates that PLTP expressed by macrophages in the site of lesion may promote RCT, but the role of systemic PLTP remains elusive.

\section{Role of PLTP in Lipoprotein Oxidation}

PLTP has vitamin E transfer activity that is important to maintain vitamin $\mathrm{E}$ level in the tissues and in the circulation. It is known that vitamin E-enriched LDL from PLTP-deficient mice is resistant to oxidation and also is much less likely to induce monocyte chemotactic activity [42, 61]. Overexpression of PLTP decreases the vitamin E content in LDL and increases its oxidation [38]. Accumulating data showed that the function of PLTP in tissues is different from its role in plasma. Studies on macrophagederived PLTP have demonstrated that PLTP deficient macrophages have more basal cholesterol level and accumulate more cholesterol in the presence of LDL [62]. Supplementary vitamin E in these animals normalizes the phenotype [62]. Thus, PLTP can modulate cholesterol deposition in macrophages through its role on oxidative status inside the cells. We have shown that PLTP-deficient hepatocytes secrete less apoB-containing lipoproteins and that this is related to premature degradation caused by lack of vitamin $\mathrm{E}$ and increased oxidation stress [63].

\section{Role of PLTP in RCT}

The role of PLTP in RCT (most of the studies were based on mouse macrophage cholesterol efflux model) is controversial. PLTP is highly expressed and regulated in macrophage cells, and this suggests its potential involvement in lipid efflux. Surprisingly, we found that the absence of PLTP does not produce significant changes in macrophage cholesterol efflux capacity [64], and this is also true for the macrophages that overexpressed PLTP [65•]. We also found that both PLTPdeficient and PLTP-transgenic mouse plasma mediates less macrophage cholesterol efflux, but after adjusting for differences in HDL cholesterol concentration (both PLTPtransgenic and deficient mice have significantly lower HDL cholesterol levels than wild-type mice) to the same levels as wild-type mouse plasma, this difference was negated (Yeang and Jiang, unpublished observation). Moreover, we found that HDL from PLTP-deficient, PLTP-transgenic, and wildtype mice has the same ability as a cholesterol acceptor (Yeang and Jiang, unpublished observation). However, there are many reports that indicate PLTP might promote or inhibit cell cholesterol efflux.

Oram et al. [52] reported that exogenous PLTP can mimic HDL apolipoprotein in removing cholesterol and phospholipids from cells by the ABCA1 pathway. Unlike apolipoproteins, however, PLTP requires the presence of HDL acceptors for its optimum activity. PLTP, therefore, appears to function as an intermediary in the transfer of excess cellular lipids to lipoproteins through its interaction with ABCA1 [52]. Oram et al. [66•] also indicated that an amphipathic helical region of the N-terminal barrel of PLTP is critical for ABCA1-dependent cholesterol efflux. Furthermore, Lee-Rueckert et al. [58] studied the ABCA1-dependent efflux of cholesterol from peritoneal macrophages derived from PLTP-deficient mice and

Table 1 Role of PLTP in cholesterol efflux and reverse cholesterol transport

\begin{tabular}{ll}
\hline Negative role & Positive role \\
\hline PLTP transgenic and knock out mice do not show significant difference & PLTP appears to be an intermediary factor in transfer of cholesterol \\
in RCT [64, 65 $]$ & {$[52]$} \\
HDL from human PLTP/apoA-I double transgenic mice is less efficient in & PLTP deficent macrophages are not able to efflux cholesterol [58] \\
RCT than apoA-I transgenic mice [70] & Active PLTP increases HDL-mediated cholesterol efflux [69] \\
High level of PLTP decreases the rate of macrophage RCT [71••] & $\begin{array}{l}\text { In hypertriglyceridemic diabetic patients, increased PLTP activity is } \\
\text { related to more cholesterol efflux [72] }\end{array}$
\end{tabular}

apoA-I apolipoprotein A-I, HDL high-density lipoprotein, PLTP phospholipid transfer protein, $R C T$ reverse cholesterol transport 
compared it with cholesterol efflux from wild-type macrophages. They found that cholesterol efflux from PLTP-deficient macrophage foam cells is defective and that the defect can be corrected by robust stimulation of the ABCA1-dependent pathway. These results support an intracellular role for endogenous macrophage PLTP in ABCA1-mediated cholesterol efflux from macrophage foam cells [58]. Based on previous studies, PLTP is present in plasma as two forms, a highly active (HA-PLTP) and a lowly active (LA-PLTP) form [67, 68]. Vikstedt et al. [69] reported that incubation of HDL in the presence of HA-PLTP resulted in the formation of pre $\beta-\mathrm{HDL}$ and caused a $42 \%$ increase in macrophage cholesterol efflux towards it, whereas LA-PLTP neither formed pre $\beta$-HDL nor increased cholesterol efflux. However, neither HA- nor LA-PLTP enhanced cholesterol efflux to lipid-free apoA-I [69]. Based on the above results, PLTP may promote macrophage cholesterol efflux.

On the other hand, Moerland et al. [70] reported that in cholesterol efflux studies from macrophages, HDL isolated from human PLTP/human apoA-I double-transgenic mice was less efficient than HDL isolated from human apoA-I transgenic mice. Furthermore, it was found that the largest subfraction of the HDL particles present in the double transgenic mice was markedly inferior as a cholesterol acceptor, as no labeled cholesterol was transferred to this fraction. These data demonstrate that the action of human PLTP in the presence of human apoA-I results in the formation of a dysfunctional HDL subfraction, which is less efficient in the uptake of cholesterol from cholesterol-laden macrophages [70]. The same group of researchers investigated the role of systemic and peripheral PLTP in macrophage cholesterol efflux and RCT in vivo. They found that macrophage cholesterol efflux and RCT to feces is impaired in PLTP transgenic mice, and that elevation of macrophage PLTP does not affect RCT, indicating that higher systemic PLTP levels may promote atherosclerosis development by decreasing the rate of macrophage RCT [71••]. The same experiment needs to be performed on PLTP-deficient mice. Based on the above results, PLTP may inhibit macrophage cholesterol efflux.

Contradictory results are also observed in human studies. De Vries et al. [72] reported that cholesterol efflux from fibroblasts to the HDL from normotriglyceridemic diabetic plasma is unchanged, whereas efflux to HDL by the source of hypertriglyceridemic diabetic plasma is enhanced, with concomitant increased plasma PLTP activity. However, Attia et al. [73] indicated that in diabetic patients with or without CHD, PLTP activity was consistently increased compared to the control group, whereas cellular cholesterol efflux activity was significantly decreased. Table 1 summarizes the reports related to the role of PLTP in cholesterol efflux and RCT.

\section{Conclusions}

Does PLTP play an import role in RCT? The answer is still not clear. PLTP clearly has a notable role in atherosclerosis that may involve its impact on lipoprotein remodelling and function. Based on published data together with our own observations, PLTP may have some impact on RCT (promoting or inhibiting), but the effect is marginal and it is difficult to draw a clear-cut conclusion. Recent data have shown that the properties of PLTP expressed locally in macrophages and tissues may be different from its function in circulation. It seems that PLTP has a proatherogenic function in the circulation. However, our knowledge about PLTP activity inside the cells is very limited. To investigate the role of PLTP in atherogenicity, other important aspects (other than RCT) need to be explored, such as lipoprotein oxidation, inflammation, apoB-containing particle assembly/secretion, intracellular functions, and so on. Further, more epidemiologic studies are needed to gain insights into the role of PLTP in atherosclerosis. Lastly, discovery of humans with genetic PLTP deficiency would be a major step toward the elucidation of the role of this transfer protein in human lipoprotein metabolism and atherosclerosis.

Disclosure The authors report no potential conflicts of interest relevant to this article.

\section{References}

Papers of particular interest, published recently, have been highlighted as:

- Of importance

-• Of major importance

1. Ross R. The pathogenesis of atherosclerosis: a perspective for the 1990s. Nature. 1993;362:801-9.

2. Witztum JL, Steinberg D. Role of oxidized low density lipoprotein in atherogenesis. J Clin Investig. 1991;88:1785-92.

3. Yla-Herttuala S, Palinski W, Rosenfeld ME, Parthasarathy S, Carew TE, Butler S, et al. Evidence for the presence of oxidatively modified low density lipoprotein in atherosclerotic lesions of rabbit and man. J Clin Investig. 1989;84:1086-95.

4. Williams KJ, Tabas I. The response-to-retention hypothesis of early atherogenesis. Arterioscler Thromb Vasc Biol. 1995;15:551-61.

5. Williams KJ, Tabas I. The response-to-retention hypothesis of atherogenesis reinforced. Curr Opin Lipidol. 1998;9:471-4.

6. Tabas I, Williams KJ, Boren J. Subendothelial lipoprotein retention as the initiating process in atherosclerosis: update and therapeutic implications. Circulation. 2007;116:1832-44.

7. Nievelstein PF, Fogelman AM, Mottino G, Frank JS. Lipid accumulation in rabbit aortic intima 2 hours after bolus infusion of low density lipoprotein. A deep-etch and immunolocalization study of ultrarapidly frozen tissue. Arterioscler Thromb. 1991;11:1795-805.

8. Tall AR, Yvan-Charvet L, Terasaka N, Pagler T, Wang N. HDL, $\mathrm{ABC}$ transporters, and cholesterol efflux: implications for the treatment of atherosclerosis. Cell Metab. 2008;7:365-75. 
9. Yvan-Charvet L, Wang N, Tall AR. Role of HDL, ABCA1, and ABCG1 transporters in cholesterol efflux and immune responses. Arterioscler Thromb Vasc Biol. 2010;30:139-43.

10. Ye D, Lammers B, Zhao Y, Meurs I, Van Berkel T, Van Eck M. ATP-Binding cassette transporters A1 and G1, HDL metabolism, cholesterol efflux, and inflammation: important targets for the treatment of atherosclerosis. Curr Drug Targets. 2010.

11. Wang X, Rader DJ. Molecular regulation of macrophage reverse cholesterol transport. Curr Opin Cardiol. 2007;22:368-72.

12. Calabresi L, Franceschini G. Lecithin:cholesterol acyltransferase, high-density lipoproteins, and atheroprotection in humans. Trends Cardiovasc Med. 2010;20:50-3.

13. Masson D, Jiang XC, Lagrost L, Tall AR. The role of plasma lipid transfer proteins in lipoprotein metabolism and atherogenesis. J Lipid Res. 2009;50(Suppl):S201-6.

14. Acton S, Rigotti A, Landschulz KT, Xu S, Hobbs HH, Krieger M. Identification of scavenger receptor SR-BI as a high density lipoprotein receptor. Science. 1996;271:518-20.

15. Fielding CJ, Fielding PE. Molecular physiology of reverse cholesterol transport. J Lipid Res. 1995;36:211-28.

16. Cuchel M, Rader DJ. Macrophage reverse cholesterol transport: key to the regression of atherosclerosis? Circulation. 2006;113:2548-55.

17. von Eckardstein A, Nofer JR, Assmann G. High density lipoproteins and arteriosclerosis. Role of cholesterol efflux and reverse cholesterol transport. Arterioscler Thromb Vasc Biol. 2001;21:13-27.

18. Movva R, Rader DJ. Laboratory assessment of HDL heterogeneity and function. Clin Chem. 2008;54:788-800.

19. Tall AR. Cholesterol efflux pathways and other potential mechanisms involved in the athero-protective effect of high density lipoproteins. J Intern Med. 2008;263:256-73.

20. Marcel YL, Ouimet M, Wang MD. Regulation of cholesterol efflux from macrophages. Curr Opin Lipidol. 2008;19:455-61.

21. Wang N, Tall AR. Regulation and mechanisms of ATP-binding cassette transporter A1-mediated cellular cholesterol efflux. Arterioscler Thromb Vasc Biol. 2003;23:1178-84.

22. Kennedy MA, Barrera GC, Nakamura K, Baldan A, Tarr P, Fishbein $\mathrm{MC}$, et al. ABCG1 has a critical role in mediating cholesterol efflux to HDL and preventing cellular lipid accumulation. Cell Metab. 2005;1:121-31.

23. Jessup W, Gelissen IC, Gaus K, Kritharides L. Roles of ATP binding cassette transporters $\mathrm{A} 1$ and $\mathrm{G} 1$, scavenger receptor $\mathrm{BI}$ and membrane lipid domains in cholesterol export from macrophages. Curr Opin Lipidol. 2006;17:247-57.

24. Silver DL, Wang N, Xiao X, Tall AR. High density lipoprotein (HDL) particle uptake mediated by scavenger receptor class $\mathrm{B}$ type 1 results in selective sorting of HDL cholesterol from protein and polarized cholesterol secretion. J Biol Chem. 2001;276:2528793.

25. Lewis GF, Rader DJ. New insights into the regulation of HDL metabolism and reverse cholesterol transport. Circ Res. 2005;96:1221-32.

26. Ansell BJ, Navab M, Hama S, Kamranpour N, Fonarow G, Hough G, et al. Inflammatory/antiinflammatory properties of high-density lipoprotein distinguish patients from control subjects better than high-density lipoprotein cholesterol levels and are favorably affected by simvastatin treatment. Circulation. 2003;108:2751-6.

27. Cockerill GW, Rye KA, Gamble JR, Vadas MA, Barter PJ. Highdensity lipoproteins inhibit cytokine-induced expression of endothelial cell adhesion molecules. Arterioscler Thromb Vasc Biol. 1995;15:1987-94.

28. Navab M, Hama SY, Hough GP, Subbanagounder G, Reddy ST, Fogelman AM. A cell-free assay for detecting HDL that is dysfunctional in preventing the formation of or inactivating oxidized phospholipids. J Lipid Res. 2001;42:1308-17.
29. Yuhanna IS, Zhu Y, Cox BE, Hahner LD, Osborne-Lawrence S, $\mathrm{Lu} \mathrm{P}$, et al. High-density lipoprotein binding to scavenger receptor-BI activates endothelial nitric oxide synthase. Nat Med. 2001;7:853-7.

30. Mineo C, Deguchi H, Griffin JH, Shaul PW. Endothelial and antithrombotic actions of HDL. Circ Res. 2006;98:1352-64.

31. Tabet F, Rye KA. High-density lipoproteins, inflammation and oxidative stress. Clin Sci (Lond). 2009;116:87-98.

32. Rothblat GH, Phillips MC. High-density lipoprotein heterogeneity and function in reverse cholesterol transport. Curr Opin Lipidol. 2010;21:229-38.

33. Albers JJ, Cheung MC. Emerging roles for phospholipid transfer protein in lipid and lipoprotein metabolism. Curr Opin Lipidol. 2004; 15:255-60.

34. Bruce C, Beamer LJ, Tall AR. The implications of the structure of the bactericidal/permeability-increasing protein on the lipidtransfer function of the cholesteryl ester transfer protein. Curr Opin Struct Biol. 1998;8:426-34.

35. Massey JB, Hickson D, She HS, Sparrow JT, Via DP, Gotto Jr AM, et al. Measurement and prediction of the rates of spontaneous transfer of phospholipids between plasma lipoproteins. Biochim Biophys Acta. 1984;794:274-80.

36. Kawano K, Qin SC, Lin M, Tall AR, Jiang XC. Cholesteryl ester transfer protein and phospholipid transfer protein have nonoverlapping functions in vivo. J Biol Chem. 2000;275:29477-81.

37. Foger B, Santamarina-Fojo S, Shamburek RD, Parrot CL, Talley GD, Brewer Jr HB. Plasma phospholipid transfer protein. Adenovirus-mediated overexpression in mice leads to decreased plasma high density lipoprotein (HDL) and enhanced hepatic uptake of phospholipids and cholesteryl esters from HDL. J Biol Chem. 1997;272:27393-400.

38. Yang XP, Yan D, Qiao C, Liu RJ, Chen JG, Li J, et al. Increased atherosclerotic lesions in apoE mice with plasma phospholipid transfer protein overexpression. Arterioscler Thromb Vasc Biol. 2003;23:1601-7.

39. van Haperen $R$, van Tol A, Vermeulen $P$, Jauhiainen $M$, van Gent $T$, van den Berg $\mathrm{P}$, et al. Human plasma phospholipid transfer protein increases the antiatherogenic potential of high density lipoproteins in transgenic mice. Arterioscler Thromb Vasc Biol. 2000;20:10828.

40. Jiang XC, Bruce C, Mar J, Lin M, Ji Y, Francone OL, et al. Targeted mutation of plasma phospholipid transfer protein gene markedly reduces high-density lipoprotein levels. J Clin Investig. 1999;103:907-14.

41. Qin S, Kawano K, Bruce C, Lin M, Bisgaier C, Tall AR, et al. Phospholipid transfer protein gene knock-out mice have low high density lipoprotein levels, due to hypercatabolism, and accumulate apoA-IV-rich lamellar lipoproteins. J Lipid Res. 2000;41:269-76

42. Yan D, Navab M, Bruce C, Fogelman AM, Jiang XC. PLTP deficiency improves the anti-inflammatory properties of HDL and reduces the ability of LDL to induce monocyte chemotactic activity. J Lipid Res. 2004;45:1852-8.

43. van Tol A. Phospholipid transfer protein. Curr Opin Lipidol. 2002;13:135-9.

44. Schlitt A, Bickel C, Thumma P, Blankenberg S, Rupprecht HJ, Meyer J, et al. High plasma phospholipid transfer protein levels as a risk factor for coronary artery disease. Arterioscler Thromb Vasc Biol. 2003;23:1857-62.

45. Cavusoglu E, Marmur JD, Chhabra S, Chopra V, Eng C, Jiang XC. Relation of baseline plasma phospholipid transfer protein (PLTP) activity to left ventricular systolic dysfunction in patients referred for coronary angiography. Atherosclerosis. 2009;207:261-5.

46. Chen X, Sun A, Mansoor A, Zou Y, Ge J, Lazar JM, et al. Plasma PLTP activity is inversely associated with HDL-C levels. Nutr Metab (Lond). 2009;6:49. 
47. Yatsuya H, Tamakoshi K, Hattori H, Otsuka R, Wada K, Zhang H, et al. Serum phospholipid transfer protein mass as a possible protective factor for coronary heart diseases. Circ J. 2004;68:11-6.

48. Schgoer W, Mueller T, Jauhiainen M, Wehinger A, Gander R, Tancevski I, et al. Low phospholipid transfer protein (PLTP) is a risk factor for peripheral atherosclerosis. Atherosclerosis. 2008;196:219-26.

49. Kathiresan S, Willer CJ, Peloso GM, Demissie S, Musunuru K, Schadt EE, et al. Common variants at 30 loci contribute to polygenic dyslipidemia. Nat Genet. 2009;41:56-65.

50. Jiang X, Francone OL, Bruce C, Milne R, Mar J, Walsh A, et al. Increased prebeta-high density lipoprotein, apolipoprotein AI, and phospholipid in mice expressing the human phospholipid transfer protein and human apolipoprotein AI transgenes. J Clin Investig. 1996;98:2373-80.

51. Valenta DT, Bulgrien JJ, Bonnet DJ, Curtiss LK. Macrophage PLTP is atheroprotective in LDLr-deficient mice with systemic PLTP deficiency. J Lipid Res. 2008;49:24-32.

52. Oram JF, Wolfbauer G, Vaughan AM, Tang C, Albers JJ. Phospholipid transfer protein interacts with and stabilizes ATPbinding cassette transporter A1 and enhances cholesterol efflux from cells. J Biol Chem. 2003;278:52379-85.

53. Wolfbauer G, Albers JJ, Oram JF. Phospholipid transfer protein enhances removal of cellular cholesterol and phospholipids by high-density lipoprotein apolipoproteins. Biochim Biophys Acta. 1999;1439:65-76.

54. Curtiss LK, Valenta DT, Hime NJ, Rye KA. What is so special about apolipoprotein AI in reverse cholesterol transport? Arterioscler Thromb Vasc Biol. 2006;26:12-9.

55. Vikstedt R, Ye D, Metso J, Hildebrand RB, Van Berkel TJ, Ehnholm C, et al. Macrophage phospholipid transfer protein contributes significantly to total plasma phospholipid transfer activity and its deficiency leads to diminished atherosclerotic lesion development. Arterioscler Thromb Vasc Biol. 2007;27:578-86.

56. Desrumaux CM, Mak PA, Boisvert WA, Masson D, Stupack D, Jauhiainen $\mathrm{M}$, et al. Phospholipid transfer protein is present in human atherosclerotic lesions and is expressed by macrophages and foam cells. J Lipid Res. 2003;44:1453-61.

57. O'Brien KD, Vuletic S, McDonald TO, Wolfbauer G, Lewis K, $\mathrm{Tu} \mathrm{AY}$, et al. Cell-associated and extracellular phospholipid transfer protein in human coronary atherosclerosis. Circulation. 2003;108:270-4.

58. Lee-Rueckert M, Vikstedt R, Metso J, Ehnholm C, Kovanen PT, Jauhiainen M. Absence of endogenous phospholipid transfer protein impairs ABCA1-dependent efflux of cholesterol from macrophage foam cells. J Lipid Res. 2006;47:1725-32.

59. Laffitte BA, Joseph SB, Chen M, Castrillo A, Repa J, Wilpitz D, et al. The phospholipid transfer protein gene is a liver $\mathrm{X}$ receptor target expressed by macrophages in atherosclerotic lesions. Mol Cell Biol. 2003;23:2182-91.

60. Liu R, Hojjati MR, Devlin CM, Hansen IH, Jiang XC. Macrophage phospholipid transfer protein deficiency and ApoE secretion: impact on mouse plasma cholesterol levels and atherosclerosis. Arterioscler Thromb Vasc Biol. 2007;27:190-6.

61. Jiang XC, Tall AR, Qin S, Lin M, Schneider M, Lalanne F, et al. Phospholipid transfer protein deficiency protects circulating lipoproteins from oxidation due to the enhanced accumulation of vitamin E. J Biol Chem. 2002;277:31850-6.
62. Ogier N, Klein A, Deckert V, Athias A, Bessede G, Le Guern N, et al. Cholesterol accumulation is increased in macrophages of phospholipid transfer protein-deficient mice: normalization by dietary alpha-tocopherol supplementation. Arterioscler Thromb Vasc Biol. 2007;27:2407-12.

63. Jiang XC, Li Z, Liu R, Yang XP, Pan M, Lagrost L, et al. Phospholipid transfer protein deficiency impairs apolipoprotein-B secretion from hepatocytes by stimulating a proteolytic pathway through a relative deficiency of vitamin $\mathrm{E}$ and an increase in intracellular oxidants. J Biol Chem. 2005;280:18336-40.

64. Cao G, Beyer TP, Yang XP, Schmidt RJ, Zhang Y, Bensch WR, et al. Phospholipid transfer protein is regulated by liver $\mathrm{X}$ receptors in vivo. J Biol Chem. 2002;277:39561-5.

65. • van Haperen R, Samyn H, Moerland M, van Gent T, Peeters M, Grosveld F, et al. Elevated expression of phospholipid transfer protein in bone marrow derived cells causes atherosclerosis. PLoS One. 2008;3:e2255. This article showed that macrophage PLTP expression has a proatherogenic property.

66. - Oram JF, Wolfbauer G, Tang C, Davidson WS, Albers JJ. An amphipathic helical region of the N-terminal barrel of phospholipid transfer protein is critical for ABCA1-dependent cholesterol efflux. J Biol Chem. 2008;283:11541-9. This article showed the interaction of PLTP and ABCA1.

67. Oka T, Kujiraoka T, Ito M, Egashira T, Takahashi S, Nanjee MN, et al. Distribution of phospholipid transfer protein in human plasma: presence of two forms of phospholipid transfer protein, one catalytically active and the other inactive. J Lipid Res. 2000;41:1651-7.

68. Murdoch SJ, Wolfbauer G, Kennedy H, Marcovina SM, Carr MC, Albers JJ. Differences in reactivity of antibodies to active versus inactive PLTP significantly impacts PLTP measurement. J Lipid Res. 2002;43:281-9.

69. Vikstedt R, Metso J, Hakala J, Olkkonen VM, Ehnholm C, Jauhiainen M. Cholesterol efflux from macrophage foam cells is enhanced by active phospholipid transfer protein through generation of two types of acceptor particles. Biochemistry. 2007;46:11979-86.

70. Moerland M, Samyn H, van Gent T, Jauhiainen M, Metso J, van Haperen R, et al. Atherogenic, enlarged, and dysfunctional HDL in human PLTP/apoA-I double transgenic mice. J Lipid Res. 2007;48:2622-31.

71. •• Samyn H, Moerland M, van Gent T, van Haperen R, Grosveld F, van Tol A, et al. Elevation of systemic PLTP, but not macrophagePLTP, impairs macrophage reverse cholesterol transport in transgenic mice. Atherosclerosis. 2009;204:429-34. This is the first article to show that elevation of systemic PLTP impairs $R C T$ in vivo.

72. de Vries R, Groen AK, Perton FG, Dallinga-Thie GM, van Wijland MJ, Dikkeschei LD, et al. Increased cholesterol efflux from cultured fibroblasts to plasma from hypertriglyceridemic type 2 diabetic patients: roles of pre beta-HDL, phospholipid transfer protein and cholesterol esterification. Atherosclerosis. 2008;196:733-41.

73. Attia N, Nakbi A, Smaoui M, Chaaba R, Moulin P, Hammami S, et al. Increased phospholipid transfer protein activity associated with the impaired cellular cholesterol efflux in type 2 diabetic subjects with coronary artery disease. Tohoku J Exp Med. 2007;213:129-37. 